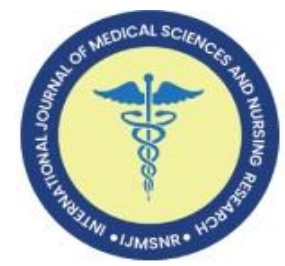

\title{
Clinical Profile and Risk Assessment of Infections Among Diabetics in a Community Health Hospital in Chennai: A Hospital Based Descriptive and Cross-Sectional Study
}

\author{
Shalini Kaliaperumal ${ }^{1}$ (ID), Ezhilan Naganathan ${ }^{2}$, Betty Chacko ${ }^{3}$
}

1, 2, ${ }^{3}$ Department of Medicine, CSI Kalyani Multi-Speciality Hospital, Chennai, Tamil Nadu, India.

\begin{abstract}
Background: Incidence of diabetes mellitus continues to rise, common focus areas for diabetes control are blood glucose levels, diet, and exercise. Controlling these factors are essential for a better quality of life in diabetes patients. Patients with diabetes have an increased risk of asymptomatic bacteriuria and pyuria, cystitis, and, more important, serious upper urinary tract infection.

Materials and Methods: This was a hospital based descriptive and cross-sectional study which included 250 Study subjects who were admitted in CSI Kalyani General hospital during the period from July 2017 to July 2018 and who has Diabetic as a comorbidity were interviewed using structured protocol based proforma. Patient underwent routine clinical, pathological and biochemical investigations.

Results: In this study, 250 in-patients were included and analyzed. The prevalence of Infection in Diabetes mellitus was 65.6\%. There is no significant association between age, education, occupation, hba $1 \mathrm{c}$, duration and type of treatment and biochemical values. The commonest organism in Urine sample among the study group was E.coli followed by Klebsiella. UTI is more common in females, respiratory infection is more common in males and it was statistically significant $(\mathrm{p}<0.009)$ and $(\mathrm{p}<0.007)$ respectively.

Conclusion: From this study, we have concluded that patient with diabetes mellitus is at increased risk for common infections due to poor glycemic control and obesity. Poor glycemic control suppresses the immunity and more prone for infection. Therefore, the challenges will be to attain good glycemic control, change in lifestyle to maintain normal BMI. This will prevent the morbimortality, reduce the long-term complication and maintenance to prolong the life without any sequele. More prospective case control studies on the management of infections in DM patients are needed.
\end{abstract}

Keywords: type 2 diabetes mellitus, infections, clinical profile, hba1c, glycemic control

Article Summary: Submitted:04-October-2021 Revised:15-November-2021 Accepted:23-December-2021 Published:31-December-2021

\begin{tabular}{|c|c|}
\hline \multirow[t]{5}{*}{ Quick Response Code: } & \multirow{3}{*}{$\begin{array}{c}\text { Web Site } \\
\text { http://ijmsnr.com/ }\end{array}$} \\
\hline & \\
\hline & \\
\hline & \\
\hline & \\
\hline
\end{tabular}

This is an open access journal, and articles are distributed under the terms of the Creative Commons Attribution-Non-Commercial-ShareAlike 4.0 International License, which allows others to remix, tweak, and build upon the work non-commercially, as long as appropriate credit is given and the new creations are licensed under the identical terms.

\section{Introduction}

Diabetes is fast gaining the status of a potential epidemic in India with more than 62 million diabetic individuals currently diagnosed with the disease. In 2000, India (31.7 million) topped the world with the highest number of people with diabetes mellitus followed by China (20.8 million) with the United States (17.7 million) in second and third place respectively. The prevalence of diabetes is predicted to double globally from 171 million in 2000 to 366 million in 2030 with a maximum increase in India. It is predicted that by 2030 diabetes mellitus may afflict up to 79.4 million individuals in India, while China (42.3 million) and the United States (30.3 million) will also see significant increases in those affected by the disease. Indians are genetically predisposed to the development of coronary artery disease due to dyslipidemia and low levels of high-density lipoproteins; these determinants make Indians more prone to development of the complications of diabetes at an early age (20-40 years) compared with Caucasians (>50 years) and indicate that diabetes must be carefully screened and monitored regardless of patient age within India. [1]

Diabetes mellitus (DM) is a common non communicable disease in India. The prevalence of type 2 DM is $11 \%$ in urban areas in comparison to $3-9 \%$ in rural areas. Infections play a significant role in morbidity and mortality of diabetic patients. Studies revealed that defect in the function of neutrophils, lymphocytes, and monocytes were the reason for increased infections in diabetics. Other reasons are low levels of leukotriene B4, thromboxane B2, and prostaglandin E. Some studies showed decreased lymphocyte function in diabetics, and decreased

How to cite this article: Kaliaperumal S, Ezhilan N, Chacko B. Clinical Profile and Risk Assessment of Infections Among Diabetics in a Community Health Hospital in Chennai: A Hospital Based Descriptive and Cross-Sectional Study. Int J Med Sci and Nurs Res 2021;1(2):1018. 
levels of phagocytosis in monocyte. There is also evidence that improving glycemic status in diabetics, improves cellular immunity. [2]

Diabetes and related complications are associated with long-term damage and failure of various organ systems. Diabetes induces changes in the microvasculature, causing extracellular matrix protein synthesis, and capillary basement membrane thickening which are the pathognomic features of diabetic microangiopathy. These changes in conjunction with advanced glycation end products, oxidative stress, low grade inflammation, and neovascularization of vasa vasorum can lead to macro vascular complications. [3] A positive association between diabetes and infection was previously the subject of debate in the literature, but recent evidence suggests that bacterial infections are a relatively frequent occurrence in diabetic patients and that there may be an associated increase in morbidity and mortality. The weight of evidence suggests that patients with type 2 diabetes have an increased incidence of common community acquired infections, including lower respiratory tract infection, urinary tract infection (UTI), and skin and mucous membrane infections. There is also a substantially increased susceptibility to rare but potentially fatal infections including necrotizing fasciitis and emphysematous pyelonephritis. [4] In patients with Diabetes mellitus, soft tissue and bone infection of the lower limbs is the most common cause for hospital admission. The rate of lower extremity amputation among diabetics is more than 40 times that of non-diabetics. [5] The risk of infection-related mortality is notably increased for diabetic adults compared with those without diabetes, but only among people with concurrent cardiovascular disease. [6]

Hepatitis $\mathrm{C}$ virus (HCV) infection may contribute to the development of diabetes mellitus. This relationship has not been investigated at the population level, and its biological mechanism remains unknown. [7] Infections are widely considered to be a source of significant health care costs and to reduce quality of life among people with diabetes mellitus (DM). A recent review of higher-quality population-based epidemiological studies found clinically important $(\sim 1.5-3.5$ times higher) infection risks associated with poorer DM control in some studies (usually defined as a glycated hemoglobin $\left[\mathrm{HbA}_{1} \mathrm{C}\right]$ level $>7-8 \%$ [53- $64 \mathrm{mmol} / \mathrm{mol}])$.

Preventing the development of diabetic complications such as infections, kidney failure, and amputations involves proper glycemic control. Addressing different aspects of diabetes control aid in the reduction of infection susceptibility. [8] Literature suggests maintaining causal blood glucose levels below $200 \mathrm{mg} / \mathrm{dL}$. Glucose levels above $200 \mathrm{mg} / \mathrm{dL}$ are expected to pose an increased risk of infections. To assist in the maintenance of proper perfusion through blood vessels, adherence to standard of care is vital. The risk and burden of infection is more in case of diabetics than in case of non-diabetic individuals. There is also evidence of altered glycemic control in diabetic patients with infection and Obesity as a risk of infection; the main of complications related with diabetes mellitus is due to impaired glucose tolerance and improper glucose control, and it has also revealed that with good glycemic control the number of complications has reduced, and also with good control of infection the glycemic control is also good. Maintaining a normal BMI is also essential to reduce the risk of disease burden among Diabetes mellitus. Although DM is very common in south India, studies on type of infections in patients with DM from rural South Indian areas are lacking. Therefore, the aim of this study was to explore this problem in our own setup. The main objectives are to study the epidemiology of infections among diabetics; to assess the risk of infections among diabetic patients; to study the clinical profile of infection among diabetic patients; and to study the common organisms isolated in Urine, Sputum and Pus sample.

\section{Materials and Methods:}

We have done this hospital based descriptive cross-sectional study in CSI Kalyani Multi-specialty hospital, Chennai with a sample of 250 patients in the study period of July 2017 - July 2018.

Sample Size Calculation: The prevalence of Infections in diabetes mellitus is $30 \%[2,10]$ We required 250 samples to estimate $30 \%$ prevalence of Infections in diabetic patients with the precision of $6 \%$ and $95 \%$ confidence interval.

$$
\mathrm{N}=\frac{Z_{(1-\alpha / 2)}^{2} * \mathrm{p}(1-\mathrm{p})}{d^{2}}
$$

$\mathrm{p}$ - Expected proportion; $\mathrm{d}$ - Precision; $\mathrm{Z}_{1-\alpha / 2}$ - Two-sided $\mathrm{Z}$ value for corresponding $\alpha ; \mathrm{N}$ - required sample size.

The inclusion criteria were both male and female patients willing to participate, in-patients in all wards, CSI Kalyani Multi-speciality Hospital with aged $>12$ years and diabetes mellitus (both Type $1 \& 2$ ) as comorbidity and with some exclusion criteria of aged less $\leq 12$ years, patient not willing for admission, non diabetic and patient not willing to participate, GDM and OPD Patients with DM. [9]

250 Study subjects, who are diabetic were included after obtaining their written consent. Patients who were admitted in CSI Kalyani General hospital during the period of July 2017 to July 2018 and who has Diabetic as a comorbidity were interviewed using structured protocol based proforma. Complete clinical examination was done. Patient underwent routine clinical, pathological and biochemical investigations such as Total count, differential, count, $\mathrm{HbA}_{1} \mathrm{C}$, FBS, PPBS, S. Urea, S. Creatinine, SGOT, SGPT were done. Appropriate microbiological investigations such as Urine c/s, Sputum c/s, Blood $\mathrm{c} / \mathrm{s}$, Pus c/s were done according to the clinical profile of the patients. Other imaging methods were done such as Chest X ray, CT Chest, CT Abdomen and CT Brain as required. Established diagnosis were documented and results were tabulated. The data collected were entered and analysed by using SPSS for Windows Version 20. Mean and Standard deviation was used for normally distributed continuous data. The dichotomous data were expressed as number and percentages. The association was found using Chi-Square test /Fisher's Exact test wherever applicable. p-value was considered as statistically significant

Ethical Consideration: This study was done with prior permission and approval from the institutional research and ethical committee and with patients' written consents and data were confidential.

\section{Results:}

This study was done among the Diabetic patients of age $>12$ years who are all treated as In-Patient during July 2017 to July 2018 in CSI Kalyani Hospital, Chennai. A total of 250 patients were analyzed and their data were given in Table - $\mathbf{1}$. 
Table - 1 Distribution of socio-demographic and clinical variables

\begin{tabular}{|c|c|c|}
\hline Variables & $\begin{array}{c}\text { Number of } \\
\text { Patients }\end{array}$ & Percentage \\
\hline \multicolumn{3}{|l|}{ Gender } \\
\hline Male & 128 & 51.2 \\
\hline Female & 122 & 48.8 \\
\hline \multicolumn{3}{|l|}{ Age (in years) } \\
\hline $30-39$ & 12 & 4.8 \\
\hline $40-49$ & 47 & 18.8 \\
\hline $50-59$ & 70 & 28.0 \\
\hline $60-69$ & 59 & 23.6 \\
\hline $70-79$ & 43 & 17.2 \\
\hline$>80$ & 19 & 7.6 \\
\hline \multicolumn{3}{|l|}{ Educational Status } \\
\hline Illiterate & 44 & 17.6 \\
\hline Primary & 11 & 4.4 \\
\hline Middle school & 54 & 21.6 \\
\hline High school & 103 & 41.2 \\
\hline Diploma & 28 & 11.2 \\
\hline Graduate & 10 & 4.0 \\
\hline Postgraduate & 0 & 0 \\
\hline \multicolumn{3}{|l|}{ Employment Status } \\
\hline Unemployed & 119 & 47.6 \\
\hline Unskilled worker & 12 & 4.8 \\
\hline Semi-skilled worker & 33 & 13.2 \\
\hline Skilled worker & 43 & 17.2 \\
\hline Clerical/shop/farm & 29 & 11.6 \\
\hline Semi professional & 14 & 5.6 \\
\hline Professional & 0 & 0 \\
\hline \multicolumn{3}{|c|}{ Duration of Diabetes Mellitus (in years) } \\
\hline$\leq 0.5$ & 36 & 14.4 \\
\hline $0.6-5.0$ & 65 & 26.0 \\
\hline $5.1-10.0$ & 79 & 31.6 \\
\hline $10.1-15.0$ & 27 & 10.8 \\
\hline $15.1-20.0$ & 28 & 11.2 \\
\hline$>20$ & 15 & 6.0 \\
\hline \multicolumn{3}{|c|}{ Types of treatment with diabetes mellitus } \\
\hline OHA & 137 & 54.8 \\
\hline Insulin & 23 & 9.2 \\
\hline Diet only & 51 & 20.4 \\
\hline Insulin \& OHA & 39 & 15.6 \\
\hline \multicolumn{3}{|c|}{ General symptoms in diabetes mellitus } \\
\hline Fever & 106 & 42.4 \\
\hline Swelling of legs & 24 & 9.6 \\
\hline Fatigue & 14 & 5.6 \\
\hline Loss of appetitie & 10 & 4.0 \\
\hline
\end{tabular}

In this study group, the prevalence of diabetes mellitus is more in the age group of $50-59$ years $(28 \%)$ followed by the age group 60 - 69 years $(23.6 \%)$, the youngest case recorded in the study is 30 years of age. In our study, both male and female nearly equal in this study. It was observed that predominant group in this study were in high school (41.2\%) followed by middle school $(21.6 \%)$. Among this study group $17.6 \%$ of the people were illiterates. Majority of them in this study group were unemployed (48\%). Majority of study group were with the duration of $5.1-10$ years $(31.6 \%)$ followed by $0.6-5.0$ years $(26 \%)$. In our present study, $54.8 \%$ of diabetics were taking only OHA's predominantly followed by $20.4 \%$ of Diabetics were on Diet only. Among the general symptoms majority of them had fever $(42.4 \%)$ followed by swelling of legs (9.6\%). In the predominant group in this study had systemic hypertension (45.6\%) followed by CAD (25.6\%) as a comorbidity.

It was observed that majority of Diabetics in this group had history of UTI in the past $(10.8 \%)$ followed by Respiratory infection in the past $(8.0 \%)$. In this study, predominant group were with the BMI of 25-29.9 (36\%), pre-obese group followed by $18.5-22.9(25 \%)$ Normal group according to Asian criteria of BMI. In this study group, $33.4 \%$ of them had Leukocytosis. In this, FBS $>126$ in 77.2 $\%$ of study group, PPBS $>140$ in $88.4 \%$ of study group, S. Urea elevated in $26.4 \%$ of study group, S. Creatinine elevated in $17.6 \%$ of study group, SGOT $>40$ in $15.2 \%$ of study group and SGPT $>40$ in $14 \%$ of study group. It is observed that, $58.8 \%$ of the study group had $\mathrm{HbA}_{1} \mathrm{C}>8$ followed by $19.6 \%$ of the study group had $\mathrm{HbA}_{1} \mathrm{C}$ 6.1 to $7 \%$. Predominant culture positivity was in Urine sample (24\%) followed by Sputum sample (14.4\%). Among the urine sample which had growth the commonest organism which was found as E.Coli (31.1\%) followed by Klebsiella (6.6\%). Among the sputum sample the commonest organism was Klebsiella (32\%). Second commonest was Mycobacterium Tuberculosis (14\%) detected by Gene Xpert method. Among the pus sample which had growth, the commonest organism was found to be Staphylococcus aureus $(33.3 \%)$ and Pseudomonas $(33.3 \%)$. Major microvascular complication in this study was found to be diabetic nephropathy (17.2\%) followed by Diabetic Retinopathy (5.6\%). Among the 250 study subjects it was observed that $65.6 \%$ of the Diabetics had Infection and $34.4 \%$ of the Diabetics had no infection. Among the study subjects the commonest infection found was Urinary infection (37.2\%) followed by Respiratory infection (21.6\%). 78.5 $\%$ of this study group had UTI, followed by Pyelonephritis (15.1 $\%$ ). It was significant that $61.6 \%$ of them had Asymptomatic UTI and respiratory infections LRTI (13.6\%) is more common.

The commonest foot infections in this study group were found to be Cellulitis (52.9\%) followed by Diabetic foot ulcer (29.4\%). Among the soft tissue infections, the commonest was found to be Candidiasis (25\%). In our study the commonest TB manifestation was found to be Pulmonary Tuberculosis (77.8\%). Moreover, Hepatitis B and Acute Gastroenteritis were distributed equal in number $(36.3 \%)$ as shown in Table-1. Infection was more common in females $(53.7 \%)$ and it was statistically significant $(\mathrm{p}=$ value 0.03 ). It was observed that infection is predominant among semiprofessional group $(71.6 \%)$ 
Kaliaperumal S et al. Clinical Profile and Risk Assessment of Infections Among Diabetics

Table - 1 Distribution of socio-demographic and clinical variables (Contd... Table-1)

\begin{tabular}{|c|c|c|}
\hline \multicolumn{3}{|c|}{ Comorbidities in Diabetes Mellitus } \\
\hline HTN & 114 & 45.6 \\
\hline CAD & 64 & 25.6 \\
\hline Anemia & 30 & 12.0 \\
\hline Dyslipidemia & 25 & 10.0 \\
\hline CKD & 23 & 9.2 \\
\hline CVA & 20 & 8.0 \\
\hline Hypothyroid & 14 & 5.6 \\
\hline Others & 52 & 20.8 \\
\hline \multicolumn{3}{|c|}{ Past infection history in diabetes mellitus } \\
\hline UTI & 27 & 10.8 \\
\hline Respiratory infection & 20 & 8.0 \\
\hline DM foot ulcer & 18 & 7.2 \\
\hline \multicolumn{3}{|l|}{ Body Mass Index in DM } \\
\hline$<18.5$ & 17 & 6.8 \\
\hline $18.5-22.9$ & 62 & 24.8 \\
\hline $23-24.9$ & 41 & 16.4 \\
\hline $25-29.9$ & 90 & 36.0 \\
\hline$\geq 30$ & 40 & 16.0 \\
\hline \multicolumn{3}{|l|}{ Total count in DM } \\
\hline Leukocytosis (>11000) & 84 & 33.6 \\
\hline Normal count (4000-11000) & 149 & 59.6 \\
\hline Leukopenia $(<4000)$ & 16 & 6.4 \\
\hline \multicolumn{3}{|l|}{ Urine Pus cells in DM } \\
\hline$<5$ & 83 & 33.2 \\
\hline 5 to 10 & 36 & 14.4 \\
\hline 10 to 20 & 26 & 10.4 \\
\hline 20 to 30 & 21 & 8.4 \\
\hline Numerous & 22 & 8.8 \\
\hline Occasional & 34 & 13.6 \\
\hline None & 28 & 11.2 \\
\hline \multicolumn{3}{|l|}{ Biochemical values in DM } \\
\hline FBS $>126$ & 193 & 77.2 \\
\hline PPBS $>140$ & 221 & 88.4 \\
\hline S. Urea $>40$ & 66 & 26.4 \\
\hline S. Creat $>1.3$ & 44 & 17.6 \\
\hline SGOT $>40$ & 38 & 15.2 \\
\hline $\mathrm{SGPT}>40$ & 35 & 14.0 \\
\hline \multicolumn{3}{|l|}{$\mathrm{HbA}_{1} \mathrm{C}$} \\
\hline 4 to $6 \%$ & 13 & 5.2 \\
\hline 6.1 to $7 \%$ & 49 & 19.6 \\
\hline 7.1 to $8 \%$ & 41 & 16.4 \\
\hline$>8 \%$ & 147 & 58.8 \\
\hline
\end{tabular}

\begin{tabular}{|c|c|c|}
\hline \multicolumn{2}{|l|}{ Positive Culture Sensitivity } & \multirow{2}{*}{$\begin{array}{c}\text { (Contd... Table-1) } \\
24.0 \\
\end{array}$} \\
\hline Urine & 60 & \\
\hline Sputum & 36 & 14.4 \\
\hline Pus & 9 & 3.6 \\
\hline Blood & 1 & 0.4 \\
\hline \multicolumn{3}{|l|}{ Organisms in Urine Sample } \\
\hline E.Coli & 38 & 31.1 \\
\hline Klebsiella & 8 & 6.6 \\
\hline Pseudomonas & 4 & 3.3 \\
\hline Staph Epidermidis & 3 & 2.5 \\
\hline Candida albicans & 2 & 1.6 \\
\hline Enterococcus & 2 & 1.6 \\
\hline Staph.aureus & 2 & 1.6 \\
\hline Non albican candida & 1 & 0.8 \\
\hline No growth & 62 & 50.8 \\
\hline \multicolumn{3}{|l|}{ Organisms in Sputum Sample } \\
\hline Klebsiella & 16 & 32.0 \\
\hline Mycobacterium Tuberculosis & 7 & 14.0 \\
\hline Pseudomonas & 6 & 12.0 \\
\hline Proteus Vulgaris & 4 & 8.0 \\
\hline Staph aureus & 3 & 6.0 \\
\hline Streptococcus & 2 & 4.0 \\
\hline E.coli & 2 & 4.0 \\
\hline Citrobacter & 1 & 2.0 \\
\hline Acinetobacter & 1 & 2.0 \\
\hline No growth & 8 & 16.0 \\
\hline \multicolumn{3}{|l|}{ Organisms in Pus sample } \\
\hline Staph Aureus & 3 & 33.3 \\
\hline Pseudomonas & 3 & 33.3 \\
\hline E.coli & 1 & 11.1 \\
\hline MRSA & 1 & 11.1 \\
\hline No growth & 1 & 11.1 \\
\hline \multicolumn{3}{|l|}{ Micro Vascular Complications } \\
\hline Nephropathy & 43 & 17.2 \\
\hline Retinopathy & 14 & 5.6 \\
\hline Neuropathy & 9 & 3.6 \\
\hline \multicolumn{3}{|l|}{ Infection in Diabetes Mellitus } \\
\hline Yes & 164 & 65.6 \\
\hline No & 86 & 34.4 \\
\hline \multicolumn{3}{|c|}{ Type of infections in Diabetes Mellitus } \\
\hline Urinary & 93 & 37.2 \\
\hline Respiratory & 54 & 21.6 \\
\hline Foot infections & 20 & 8.0 \\
\hline Skin and soft tissue & 15 & 6.0 \\
\hline Tuberculosis & 9 & 3.6 \\
\hline Cholecystitis & 2 & 0.8 \\
\hline Others & 19 & 7.6 \\
\hline
\end{tabular}


Table - 2 Association between with and without infection among diabetes patients

\begin{tabular}{|c|c|c|c|c|c|c|}
\hline \multirow{2}{*}{ Variables } & \multicolumn{2}{|c|}{$\begin{array}{c}\begin{array}{c}\text { With Infection } \\
n=164\end{array} \\
\end{array}$} & \multicolumn{2}{|c|}{$\begin{array}{c}\begin{array}{c}\text { Without infection } \\
n=86\end{array} \\
\end{array}$} & \multirow{2}{*}{$\begin{array}{c}\text { Total } \\
(\mathbf{N}=\mathbf{2 5 0})\end{array}$} & \multirow{2}{*}{ p-value } \\
\hline & Number & Percentage & Number & Percentage & & \\
\hline \multicolumn{7}{|l|}{ Gender } \\
\hline Male & 76 & 46.3 & 52 & 60.5 & 128 & \multirow{2}{*}{0.030} \\
\hline Female & 88 & 53.7 & 34 & 39.5 & 122 & \\
\hline \multicolumn{7}{|c|}{ Occupational Status } \\
\hline Unemployed & 84 & 70.6 & 35 & 29.4 & 119 & \multirow{7}{*}{0.418} \\
\hline Unskilled & 6 & 50.0 & 6 & 50.0 & 12 & \\
\hline Semiskilled & 17 & 51.5 & 16 & 48.5 & 33 & \\
\hline Skilled & 27 & 62.8 & 16 & 37.2 & 43 & \\
\hline Farm & 20 & 69.0 & 9 & 31.0 & 29 & \\
\hline $\begin{array}{l}\text { Semi } \\
\text { professional }\end{array}$ & 10 & 71.4 & 4 & 28.6 & 14 & \\
\hline Professional & 0 & 0 & 0 & 0 & 0 & \\
\hline \multicolumn{7}{|c|}{ Duration with infection (in years) } \\
\hline $0-0.5$ & 19 & 52.8 & 17 & 47.2 & 36 & \multirow{6}{*}{0.070} \\
\hline $0.6-5.0$ & 50 & 76.9 & 15 & 23.1 & 65 & \\
\hline $5.1-10.0$ & 53 & 67.1 & 26 & 32.9 & 79 & \\
\hline $10.1-15.0$ & 14 & 51.9 & 13 & 48.1 & 27 & \\
\hline $15.1-20.0$ & 20 & 71.4 & 8 & 28.6 & 28 & \\
\hline$>20$ & 8 & 53.3 & 7 & 46.7 & 15 & \\
\hline \multicolumn{7}{|c|}{ Types of treatm ent } \\
\hline $\mathrm{OHA}$ & 92 & 67.2 & 45 & 32.8 & 137 & \multirow{3}{*}{]$^{0.355}$} \\
\hline Insulin & 12 & 52.2 & 11 & 47.8 & 23 & \\
\hline Diet only & 35 & 68.6 & 16 & 31.4 & 51 & \\
\hline $\begin{array}{l}\text { Insulin and } \\
\text { OHA }\end{array}$ & 25 & 64.1 & 14 & 35.9 & 39 & $\sqrt{0.170}$ \\
\hline \multicolumn{7}{|l|}{ Com orbidities } \\
\hline SHTN & 75 & 45.7 & 39 & 45.3 & 114 & 0.950 \\
\hline $\mathrm{CAD}$ & 44 & 26.8 & 20 & 23.3 & 64 & 0.530 \\
\hline Anemia & 21 & 12.8 & 9 & 10.5 & 30 & 0.580 \\
\hline Dyslipidemia & 11 & 6.7 & 14 & 16.3 & 25 & 0.010 \\
\hline $\mathrm{CKD}$ & 14 & 8.5 & 9 & 10.5 & 23 & 0.610 \\
\hline CVA & 8 & 4.9 & 12 & 14.0 & 20 & 0.010 \\
\hline Hypothyroid & 9 & 5.5 & 5 & 5.8 & 14 & 0.910 \\
\hline
\end{tabular}

and unemployed (70.6\%) and it not statistically significant with pvalue $=0.418(>0.05)$. In our study, infection is more common when the duration of diabetes is $0.6-5$ years $(76.9 \%)$ followed by $15.1-20$ years $(71.4 \%)$ and this was not statistically significant with p-value $=0.070$ $(>0.05)$.

Infection is more common in diabetics who are only on diet and only on OHA. Among the Diabetics who are only on diet, $68.6 \%$ of them had infection and Diabetics who are only on OHA, nearly $67.2 \%$ of them had infections. It was not statistically significant with $\mathrm{p}>0.05$.

It was not statistically significant with $\mathrm{p}>0.05$. It is observed that infection is more common in diabetics who had systemic hypertension as a comorbidity but this was not statistically significant ( $>0.05$ ). However, Infection was less common in Dyslipidemia and CVA group and it was highly statistically significant $(\mathrm{p}<0.01)$.
It is observed that infection is more common in underweight group $(\mathrm{BMI}<18.5)$ followed by obese group $(\mathrm{BMI}>30)$ and the test was showed statistically highly significant ( $\mathrm{p}$-value $<0.01$ ) as shown in Figure-1.

Figure: 1 Comparison of Body Mass Index and with Infection

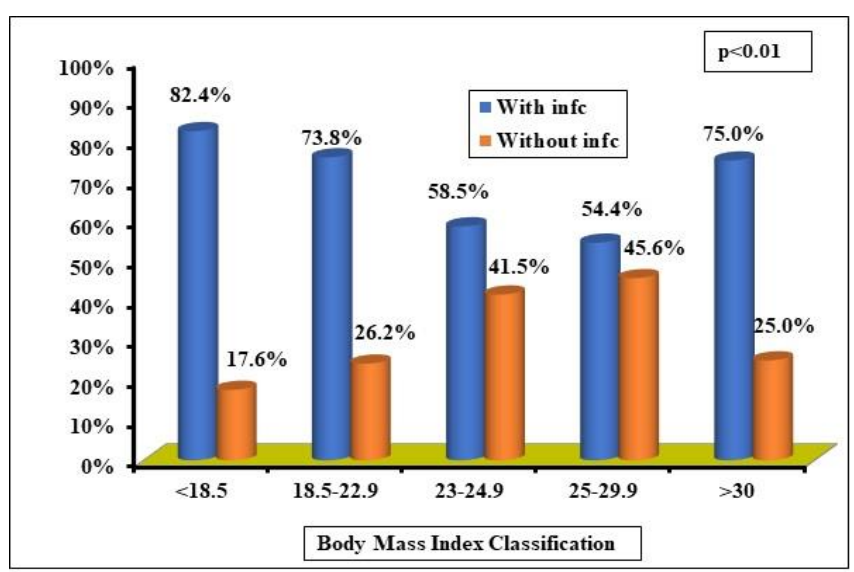

In our present study, $68.2 \%$ of the Diabetics with Urinary symptoms had positive urine culture and this was statistically significant ( $\mathrm{p}$ value $<0.001$ ) as shown in Figure-2.

Figure: 2 Comparison of urinary symptoms with urine $\mathrm{c} / \mathrm{s}$

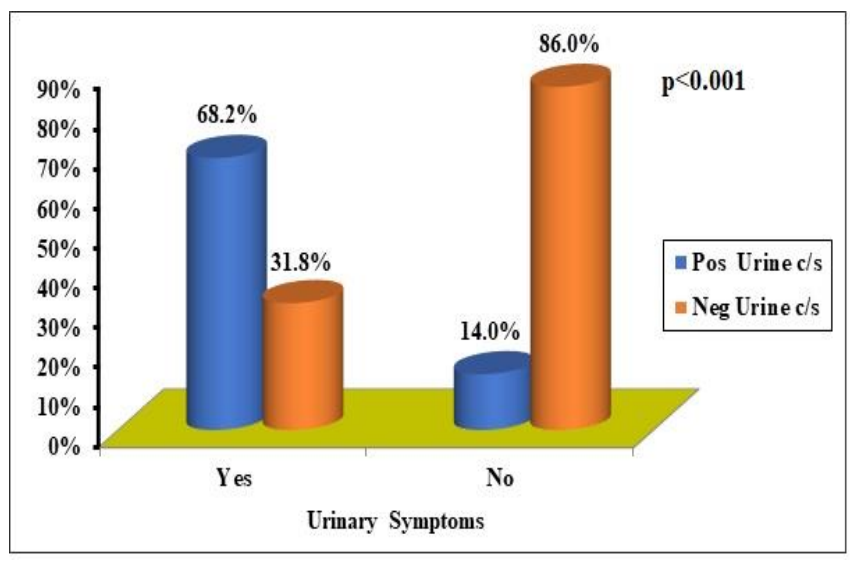

\section{Discussion:}

Diabetes Mellitus [12] is a non-communicable disease and is one of the major disease burdens worldwide and also a leading cause for non-traumatic lower limb amputations, the association of the Infection and diabetes mellitus is not a new entity it's been known for quite some time for now, the recent studies also suggest the 
prevalence of infections among diabetics with, many research has also proved that glycemic control within appropriate normal limits will also help to reduce the morbimortality and long-term complications [14] of Diabetes mellitus. [11, 12] Physicians should be aware of risk factors and type of infections present in patients with diabetes in order to provide proper care. Prospective studies on the management of infections in patients with diabetes mellitus are needed. [13] Diabetic retinopathy is a major complication of DM. $[15,16]$ Diabetic neuropathy is also a complication of $\mathrm{DM}$ and insulin complications in the long-term. [17, 18, 19, 20]

Other type of infections is also happening to DM patients. [21] Complete clinical examination was done. Patient underwent routine clinical, pathological and biochemical investigations such as Total count, differential, count, $\mathrm{HbA}_{1} \mathrm{C}$, FBS, PPBS, S. Urea, S. Creatinine, SGOT, SGPT were done. Appropriate microbiological investigations [21, 22, 23] such as Sputum c/s [24], Urine c/s [25, 26], Blood c/s, Pus c/s [26] were done according to the clinical profile of the patients. Other imaging methods were done such as Chest X ray, CT Chest, CT Abdomen and CT Brain as required. Established diagnosis were documented and results were tabulated as per results. $[24,26]$

In our study the number of male and female were equal. Mean age of study subject was 60 years. In my study, the maximum number of Diabetics with infection were seen in $50-59$ years' age group $(78.3 \%)$. This increase in incidence of infection with age was observed in a study by Gillani et al. [27] However there was no statistical significance with age and infection in my study. In my study the infection rate was higher among females $(53.7 \%)$. However, this was not statistically significant. UTI is more common in females $(36.9 \%)$ and this was statistically significant $(\mathrm{p}=0.009)$. Similarly, in Al-Rubeaan et al study, the prevalence of UTI was more common in diabetic females. [28] In my study Age, duration of diabetes and $\mathrm{HbA}_{1} \mathrm{C}$ did not influence the incidence of infection and there is no statistical significance, while BMI above $30 \mathrm{~kg} / \mathrm{m}^{2}$ increased the risk of infection and it is statistically significant $(\mathrm{p}<0.01)$. Similar statistical significance observed in Al-Rubeaan et al study. [28] In my study respiratory infection is more common in males $(23.4 \%)$ and it was statistically significant $(\mathrm{p}=0.007)$. Similarly, in Dutt and Dabhi study, male patients and uncontrolled DM had higher prevalence on pneumonia associated with diabetes. [29] In this study it was also revealed that there was no significant statistical association between Education, Occupation, Type of treatment, biochemical values and $\mathrm{HbA}_{1} \mathrm{C}$ with infections among diabetics. However, $58.8 \%$ of them had $\mathrm{HbA}_{1} \mathrm{C}>8 \%$, and infection is less common with $\mathrm{HbA}_{1} \mathrm{C}$, 4 to $6 \%$ but it wasn't statistically significant. In Critchley et al study, it was observed that long-term infection risk rose with increasing $\mathrm{HbA}_{1} \mathrm{C}$ for most outcomes. Poor glycemic control was powerfully associated with serious infections and should be a high priority. [30] In our study there was a positive correlation that the risk of infection is high in diabetics who are on diet only (68.6\%) and only on Oral hypoglycemic agents (67.2\%). There was a positive correlation observed that Diabetics who are on Insulin has good control of blood sugars and less prone to infection. But this was not statistically significant with $\mathrm{p}>0.05$. However, in a study by Ooi et al, it was statistically significant that Intensive insulin therapy and tight glycemic control were associated with a lower risk of infection. [31] Out of 250 study subjects, 164 diabetics had infections and 86 diabetic patients without infections. In our study, the prevalence of infections among Diabetics was $65.6 \%$. The predominant infections encountered were Urinary infection $(37.2 \%)$, Respiratory infection (21.6\%), Foot infections (8.0\%), Skin and soft tissue infections (6.0\%), Tuberculosis (3.6\%) and Cholecystitis (0.8\%). Escherichia coli (31.1\%) and Klebsiella (6.6\%) were the commonest organisms isolated from urine sample. Klebsiella (32\%) and Mycobacterium tuberculosis (14\%) were the commonest organism isolated from the sputum sample. In a retrospective study was done by Bettegowde et al. from a rural Tertiary care hospital of South Karnataka, out of 842 diabetics, 254 $(30.1 \%)$ had infections. The commonest comorbidity was Hypertension (62.99\%). Common infections encountered were upper respiratory tract infection $(29.13 \%)$, urinary tract infection $(26.77 \%)$, Lower respiratory tract infection (15.74\%), Tuberculosis $(11.81 \%)$, Skin and soft tissue infections (11.02\%) and Foot infections (8.66\%). Escherichia coli and Candida albicans were the common causative organisms of urinary tract infection. Staphylococcus aureus and Mycobacterium tuberculosis were the most common microorganisms causing respiratory tract infections. [2]

In my study urinary infection (37.2\%), Respiratory infection $(21.6 \%)$, foot infection (8.0\%), Skin and soft tissue infection $(6.0 \%)$, Tuberculosis (3.6\%) and Cholecystitis (0.8\%). In Sow et al. study the mean infections were the skin and soft tissues $(54.91 \%)$, urogenital infections (16.18\%), respiratory infections (14.45\%), malaria $(3.46 \%)$, infections of the skin and soft tissues were dominated by the diabetic foot $(41.90 \%)$. [32] In our study positive correlation found between Asymptomatic UTI and Diabetic patients. Out of $77.4 \%$ of Urinary tract infection, $66 \%$ of the Diabetics had an Asymptomatic UTI. Similarly, in Bissong et. al. study, it was observed that there was a high prevalence of ASB in diabetics than in non-diabetics. [33]

In my study the common organism isolated from urine sample was found to be E.coli $(31.1 \%)$ followed by Klebsiella (6.6\%). Similarly, in Aswani et al study, a total of 181 diabetics ( 83 males and 98 females) and 124 non-diabetic subjects (52 males and 72 females) with culture positive UTI were studied. The isolation rate of Escherichia coli (E. coli) from urine culture was higher (64.6 per cent) among diabetic patients followed by Klebsiella (12.1 per cent) and Enterococcus (9.9 per cent). [34] The present study revealed that Klebsiella were the commonest organism isolated from Sputum sample. Similarly, in Saibal et al [35] study totally 47 diabetics and 43 non-diabetic adult hospitalized patients with CAP were enrolled. Klebsiella pneumoniae was the most frequent causative pathogen for CAP in diabetic patients, whereas Streptococcus pneumoniae was the most frequent causative agent for non-diabetic patients. [36] In the present study the common organism isolated in Pus sample was Staphylococcus aureus (33.3\%) and Pseudomonas (33.3\%), which is similar to a study done by Banu et al. [37], prospective study done at a tertiary care hospital, one hundred patients over the age of 18 , having chronic diabetic foot ulcer, and attending the surgery outpatient department were included Staphylococcus aureus was the predominant organism, followed by Pseudomonas aeruginosa. In my study there is a positive correlation that oral candidiasis is common in diabetics. Similarly, in a study done by Radmila R. et al it was concluded that oral candidiasis is significantly more frequent in diabetic patients compared to the non-diabetic subjects. [32, 38, 39] In our study the predominant comorbidity was systemic hypertension $(45.6 \%)$ followed by CAD (25.6\%), Dyslipidemia (10\%), CKD (9.2\%), CVA (8\%), NAFLD (7.6\%) and PVD (0.8\%). 
The predominant microvascular complication among the study group was Diabetic Nephropathy (17.2\%) followed by Diabetic Retinopathy (5.6\%) and Diabetic Neuropathy (3.6\%). However in Behera et al study, there was high prevalence of vascular complications and infections in T2DM patients. Of the total patients, 56\% had nephropathy, $20 \%$ neuropathy, $17.3 \%$ retinopathy, $31.3 \%$ CVD, $11.3 \%$ CAD, $4.6 \%$ acute metabolic complications, $44 \%$ infections and $16.6 \%$ had NAFLD respectively. Macrovascular events occurred earlier than microvascular complications. [11] In our study, the prevalence of Herpes zoster was $6.3 \%$ and there was a positive correlation that Diabetes increases the risk of Herpes zoster. Similarly, in a retrospective study was done by Guignard et al. [40], revealed that type II diabetes was associated with an increased risk of developing HZ, which was particularly high in adults 65 years and older and moderately increased in adults under 65 years of age.

\section{Conclusion:}

This study revealed that infection is more common in females rather than males. The risk of infection increases with the duration of diabetes. Infection is predominant in Diabetics who are only on diet and only on Oral hypoglycemic agents. Majority of them in this study group had $\mathrm{HbA}_{1} \mathrm{C}>8 \%$ which highlights that the risk of increases with poor glycemic control. Majority of the Diabetics had past history of Urinary tract and Respiratory tract infection. It is highlighted that infection rate increases in Underweight $(\mathrm{BMI}<18.5)$ and Obese group BMI $(>30)$. Majority of them in this study had Systemic Hypertension and Coronary artery disease as a comorbidity.

The commonest microvascular complication in this study was Diabetic Nephropathy followed by Diabetic Retinopathy. The commonest infection found was Urinary tract infection, Respiratory infection, Foot infection, Skin and soft tissue infection, Tuberculosis and Cholecystitis. Urinary Tract Infection (UTI) is common in age group 60-69 years and Respiratory infection is common in age group $>80$ years. UTI is more common in females and Respiratory infection more common in males. The commonest organism isolated in urine sample was E.coli followed by Klebsiella.

The commonest organism in sputum sample was Klebsiella followed by Mycobacterium tuberculosis. Hence good glycemic control, proper maintenance and maintaining an appropriate BMI especially in long duration of diabetics is essential to reduce long term complications and infections. It is essential that appropriate screening measures should be initiated at an early stage.

\section{Recommendations:}

This study is based on local small population and therefore has limitations, it is recommended that wider areas must be covered to find out the incidence and prevalence of infections in diabetes mellitus. More prolonged duration of study is needed to identify the wide spectrum of diseases among the Diabetics. Infection, which has been demonstrated to be significantly associated with diabetics must therefore be identified and treated at an early stage to reduce the consequence of both uncontrolled Diabetes and infections and to reduce the morbimortality.
Diabetic screening for all adult patients who are all coming with infection is mandatory to reduce the mortality and morbidity associated with it. Diabetic screening tests should be mandatory at their first visit to the hospital above 30 years of age and then every 3 years to reduce long term complication of Diabetes mellitus. Further studies are required to find out the morbimortality of infections among diabetic patients.

\section{Limitations:}

As it is a hospital-based study, this cannot be extrapolated to the general population. Patient who was not willing to participate in the study could not be included, thereby the exact prevalence of infection in diabetics could not find out. As this study done only in inpatients with diabetics, OP patients with diabetics and infection could not be assessed. As it was a cross sectional study, the outcome after treating infection could not be measured. The morbimortality of infection in diabetics could not be assessed as there is no follow up in this study.

Authors Contributions: SK, EN, BC: Conception and design.: Acquisition of Data. EN, BC: Analysis and Interpretation of data. All authors SK, EN, BC: Drafting the article, revising it for Intellectual content. All authors were checked and approved of the final version of the manuscript.

Here, SK: Shalini Kaliaperumal; EN: Ezhilan Naganathan; and BC: Betty Chacko

Source of funding: We didn't get any types of financial support from our parent institution and any other financial organization.

Conflict of Interest: The authors declared no conflict of interest

\section{Abbreviations:}

FBS - Fasting blood sugar

PPBS - Post prandial blood sugar

BMI - Body mass index

OHA - Oral Hypoglycemic agent

UTI - Urinary tract infection

LRTI - Lower respiratory tract infection

URTI - Upper respiratory tract infection

TB - Tuberculosis

CAP - Community acquired pneumonia

CAD - Coronary Artery disease

CKD - Chronic Kidney Disease

SHTN - Systemic hypertension

PVD - Peripheral vascular disease 
CVA - Cerebrovascular accident

NAFLD - Non-alcoholic fatty liver disease

AGE - Acute gastroenteritis

CSOM - Chronic suppurative otitis media

MRSA - Methicillin Resistant staphylococcus aureus

USG - Ultrasonography

CT - Computed Tomography

ATT-Antitubercular drugs

BP - Blood pressure

\section{References:}

1. Kaveeshwar SA, Cornwall J. The current state of diabetes mellitus in India. Australas Med J. 2014;7(1):45-48. PMID: 24567766

2. Bettegowda S, Iyengar VS, and Gosain V. Clinical profile and Spectrum of Infections in Type 2 Diabetes Mellitus Patients: A Retrospective Study from Rural Tertiary Care Hospital of South Karnataka, India. Scholars Journal of Applied Medical Sciences 2014;2:3331-3336. DOI: 10.4103/0971-4065.57107.

3. Chawla A, Chawla R, Jaggi S. Microvasular and macrovascular complications in diabetes mellitus: Distinct or continuum? Indian J Endocrinol Metab. 2016;20(4):546-551. DOI: 10.4103/22308210.183480

4. Hamilton EJ, Martin N, Makepeace A, Sillars BA, Davis WA, Davis TME. Incidence and Predictors of Hospitalization for Bacterial Infection in Community-Based Patients with Type 2 Diabetes: The Fremantle Diabetes Study. PLoS ONE 2013;8(3):e60502. DOI: 10.1371/journal.pone.0060502

5. El-Sheikh S, Johargi A. Bacterial and Fungal Infections Among Diabetics. J King Abdulaziz Univ-Med Sci 2000;8(1):41-48.

6. Shah BR, Hux JE. Quantifying the Risk of Infectious Diseases for People With Diabetes. Diabetes Care 2003 Feb 1;26(2):510-513. DOI: $10.2337 /$ diacare.26.2.510

7. Mehta SH, Brancati FL, Sulowski MS, Strathdee SA, Szklo M, Thomas DL. Prevalence of Type 2 Diabetes Mellitus among Persons with Hepatitis C Virus Infection in the United States. Ann Intern Med. 2000;133(8):592-599. PMID: 11033586

8. History of Diabetes. News-Medical.net. 2009. Available from: https://www.news-medical.net/health/History-of-Diabetes.aspx [Last Accessed on: 06 July 2017]

9. American Diabetes Association. Diagnosis and Classification of Diabetes Mellitus. Diabetes Care 2013;36(Supplement 1):S67S74.

10. Zimmet P, Alberti KG, Magliano DJ, Bennett PH. Diabetes mellitus statistics on prevalence and mortality: facts and fallacies. Nat Rev Endocrinol 2016;12(10):616-622. PMID: 27388988

11. Behera SR, Behera M, Das S, Panda BP, Tripathy SK, Dash PC. Morbidity Profile and Causes of Mortality in Type 2 Diabetes Patients: Data from a Tertiary Teaching Hospital from Eastern India. Journal of Diabetes Mellitus 2017;7(3):195-211. DOI: 10.4236/jdm.2017.73016

12. Types of Diabetes Mellitus. WebMD. Available from: https://www.webmd.com/diabetes/guide/types-of-diabetesmellitus [Last Accessed on: 03 July 2017]
13. Mubarak H. Diabetes Mellitus. Medical Textbook in The Net. 2008. Available from: https://emedicaltextbook.blogspot.com/2008/08/diabetes-mellitus.html [Last Accessed on: 10 August 2017]

14. Nathan DM. Long-Term Complications of Diabetes Mellitus. N Engl J Med 1993;328(23):1676-1685. PMID: 8487827

15. Diabetic Retinopathy. Available from: https://www.eyeops.com/practice_content_page_grandchild/our -services/eye-diseases/diabetic-retinopathy [Last Accessed on: 12 August 2017]

16. Diabetes Mellitus: Management of Microvascular and Macrovascular Complications. Available from: http://www.clevelandclinicmeded.com/medicalpubs/diseasema nagement/endocrinology/diabetes-mellitus/ [Last Accessed on: 14 September 2017]

17. Team HJ. Diabetic Neuropathy - Causes, Symptoms, Signs, Medications, Treatment. Health Jade 2018. Available from: https://healthjade.com/diabetic-neuropathy/ [Last Accessed on: 14 August 2017]

18. Chatterjee S, Davies MJ. Current management of diabetes mellitus and future directions in care. Postgrad Med J 2015;91(1081):612-621. PMID: 26453594

19. Drive ADA 2451 C, Arlington S 900, Va 22202 1-800-Diabetes. Insulin Basics. American Diabetes Association. Available from: http://www.diabetes.org/living-with-diabetes/treatment-andcare/medication/insulin/insulin-basics.html [Last Accessed on: 20 December 2017]

20. Casqueiro J, Casqueiro J, Alves C. Infections in patients with diabetes mellitus: A review of pathogenesis. Indian J Endocrinol Metab 2012;16Suppl 1(Suppl1):S27-S36. PMID: 22701840

21. Burman WJ, McCollister BD, Knepper BC, Jason Moore S, Perlman DM, Jenkins TC, et al. Comparison of the microbiology and antibiotic treatment among diabetic and non-diabetic patients hospitalized for cellulitis or cutaneous abscess. J Hosp Med 2014;9(12). Available from: https://www.journalofhospitalmedicine.com/jhospmed/article/1 27319/diabetes-mellitus-and-skin-infections

22. Muller LMAJ, Gorter KJ, Hak E, Goudzwaard WL, Schellevis FG, Hoepelman AIM, et al. Increased Risk of Common Infections in Patients with Type 1 and Type 2 Diabetes Mellitus. Clin Infect Dis 2005;41(3):281-288. DOI: 10.1086/431587

23. Aswani SM, Chandrashekar UK, Shivashankara KN, Pruthvi BC. Clinical profile of urinary tract infections in diabetics and non-diabetics. Australas Med J 2014;7(1):29-34. PMID: 24567764

24. Viswanathan V, Kumpatla S, Aravindalochanan V, Rajan R, Chinnasamy C, Srinivasan R, et al. Prevalence of Diabetes and Pre-Diabetes and Associated Risk Factors among Tuberculosis Patients in India. Pai M, editor. PLoS ONE 2012;7(7):e41367. DOI: 10.1371 journal.pone.0041367

25. Karunajeewa H, McGechie D, Stuccio G, Stingemore N, Davis WA, Davis TME. Asymptomatic bacteriuria as a predictor of subsequent hospitalisation with urinary tract infection in diabetic adults: The Fremantle Diabetes Study. Diabetologia 2005;48(7):1288-1291. PMID: 15918016

26. Zhang Q, Xiao H, Sugawara I. Tuberculosis complicated by diabetes mellitus at shanghai pulmonary hospital, china. Jpn J Infect Dis 2009;62(5):390-391. PMID: 19762992 
Kaliaperumal S et al. Clinical Profile and Risk Assessment of Infections Among Diabetics

27. Gillani SW, Sulaiman SAS, Sundram S, Sari YO, Baig M, Iqbal MMS. Serological Prediction of infections in Diabetic Patients with Diabetes Ketoacidosis in Penang, Malaysia. Trop J Pharm Res 2012;11(5):815-821. DOI: 10.4314/tjpr.v11i5.16

28. Al-Rubeaan KA, Moharram O, Al-Naqeb D, Hassan A, Rafiullah MRM. Prevalence of urinary tract infection and risk factors among Saudi patients with diabetes. World J Urol 2013;31(3):573-578.

29. Dutt J, Dabhi L. Study of pneumonia in diabetic patients. Int J Med Sci Public Health 2014;3(8):974-976.

30. Kim Y, Wie S-H, Chang U-I, Kim J, Ki M, Cho YK, et al. Comparison of the clinical characteristics of diabetic and nondiabetic women with community-acquired acute pyelonephritis: a multicenter study. J Infect 2014;69(3):244-251.

31. Ooi YC, Dagi TF, Maltenfort M, Rincon F, Vibbert M, Jabbour P, et al. Tight glycemic control reduces infection and improves neurological outcome in critically ill neurosurgical and neurological patients. Neurosurgery 2012;71(3):692-702. PMID: 22688953

32. Geerlings SE, Meiland R, van Lith EC, Brouwer EC, Gaastra W, Hoepelman IM. Adherence of type 1-fimbriated Escherichia coli to uroepithelial cells: more in diabetic women than in control subjects. Diabetes Care 2002;25(8):1405-1409.

33. Bissong MEA, Fon PN, Tabe-Besong FO, Akenji TN. Asymptomatic bacteriuria in diabetes mellitus patients in Southwest Cameroon. Afr Health Sci 2013;13(3):661-666.

34. Aswani SM, Chandrashekar U, Shivashankara K, Pruthvi B. Clinical profile of urinary tract infections in diabetics and nondiabetics. Australas Med J 2014;7(1):29-34.

35. Saibal MA, Rahman SHZ, Nishat L, Sikder NH, Begum SA, Islam $\mathrm{MJ}$, et al. Community acquired pneumonia in diabetic and nondiabetic hospitalized patients: presentation, causative pathogens and outcome. Bangladesh Med Res Counc Bull 2012;38(3):98103.

36. Walters DP, Gatling W, Mullee MA, Hill RD. The distribution and severity of diabetic foot disease: a community study with comparison to a non-diabetic group. Diabet Med J Br Diabet Assoc 1992;9(4):354-358. PMID: 1600707

37. Banu A, Noorul Hassan MM, Rajkumar J, Srinivasa S. Spectrum of bacteria associated with diabetic foot ulcer and biofilm formation: A prospective study. Australas Med J 2015;8(9):280 285.

38. Radmila RO, Kesić L, Pejcic A, Petrovic MS, Zivkovic ND, Dusan Z. Diabetes mellitus and oral candidiasis. Acta Stomatol Naissi 2011;27(63):1025-1034. DOI: 10.5937/asn11630250.

39. Sow D, Diédhiou D, Diallo IM, Ndour MA, Diouf M, Ka-Cissé M, et al. Morbi Infectious Mortality of Diabetics Hospitalized at the Medical Clinic of Abass Ndao Health Center. Open J Endocr Metab Dis 2018;8(1):1-8. DOI: 10.4236/ojemd.2018.81001.

40. Guignard AP, Greenberg ME, Lu C, Rosillon D, Vannappagari V. Risk of herpes zoster among diabetics: A matched cohort study in a US insurance claim database before introduction of vaccination, 1997-2006. Infection 2014;42:729-735. DOI: 10.1007/s15010014-0645-x.

Publish your research article with International Journal of Medical Sciences and Nursing Research Website: http://ijmsnr.com/ 